\title{
Performance Evaluation of Bathymetry Data using Statistical Techniques to Remove Underwater Noise
}

\author{
M. Selva Balan \\ Scientist D CWPRS\& \\ Research \\ Scholar, DIAT \\ Pune, India
}

\author{
C. R. S. Kumar, PhD \\ Associate Professor \\ Computer Engineering \\ Division \\ DIAT, Pune, India
}

\author{
Km. Anjali Singh \\ PG Student \\ E\&TC Department \\ SCOE Pune, India
}

\author{
Shini K. K \\ Dy Director \\ Keri \\ Peechi, India
}

\begin{abstract}
Analysis of bathymetry information is a testing errand because of a few reasons. The information is gathered remotely which is huge in size. Bathymetry information contains the profundity estimations of water body at different areas. The data obtained is also affected by noise and needs to be processed to predict the bottom of reservoir and water body. This data is prepared to produce a 3D plot by introducing the transitional estimations of the plot. The bathymetry information comprises of different commotions which are evacuated by applying noise expulsion calculations lastly the volume of water is anticipated. This paper presents different noise evacuation systems on bathymetry information to anticipate the volume of water in a supply.
\end{abstract}

\section{Keywords}

Bathymetry data, gridding, multipath noise, noise, interpolation

\section{INTRODUCTION}

The phase of development and construction of reservoirs will be ending into a phase of defining management and operating policies for reservoirs against sedimentation issues. Rivers are carrier channels for both water and sediments entrapped in the flow, impounding of water in the reservoir is aimed for but silting of sediment carried by the flow need to be checked. Siltation of sediments in reservoir brings down benefits dwelled by it. Dams in any nation are a piece of a few multireason tasks to serve an assortment of necessities. Fundamentally, dams are worked to outfit the waterway water with the goal that it very well may be used by the necessities. A multipurpose undertaking is regularly propelled for putting away water for water system purposes, giving drinking water and creating hydro-power.

Bathymetry is the investigation of submerged profundity of lake or sea floor. As it were, bathymetry is the submerged identical to hypsometryor geology. The name originates from

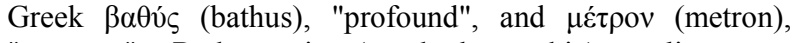
"measure". Bathymetric (or hydrographic) outlines are frequently made to help prosperity of surface or sub-surface course, and by and large demonstrate sea base mitigation or landscape as shape lines (called profundity forms or isobaths) and chose profundities (soundings), and ordinarily additionally give surface navigational data. Bathymetric maps (a more broad term where navigational security isn't a worry) may likewise utilize a Digital Terrain Model and fake light strategies to represent the profundities being depicted. The worldwide bathymetry is some of the time joined with geography information to yield a Global Relief Model. Pale bathymetry is the investigation of past submerged profundities.Hydrological cycle and natural geology provide sites and locations, such that maximum benefits can be derived out of it by the construction of a water storage structure. For data collection, dual frequency (Single beam echo sounder).Recently, multibeam echo sounder is using for data collection, which provide high accuracy, depth and coverage. The bathymetry data obtained using single beam echo sounder is a part of Geographical Information system (GIS) that collect the data in $\mathrm{X}, \mathrm{Y}$ and $\mathrm{Z}$ format. The $\mathrm{X}$ and $\mathrm{Y}$ values are the geographical coordinator's obtained By GPS and $\mathrm{Z}$ is the depth received from the echo sounder.The rest of part of paper is organized as follow. Section II describe the proposed system. Section III result and discussion and Section IV conclusion of proposed system.

\section{PROPOSED SYSTEM}

The components of a bathymetry data analysis are describe in figure 1.The System First receive the bathymetry data, followed by the noise removal and interpolation. In the last volume will be estimated

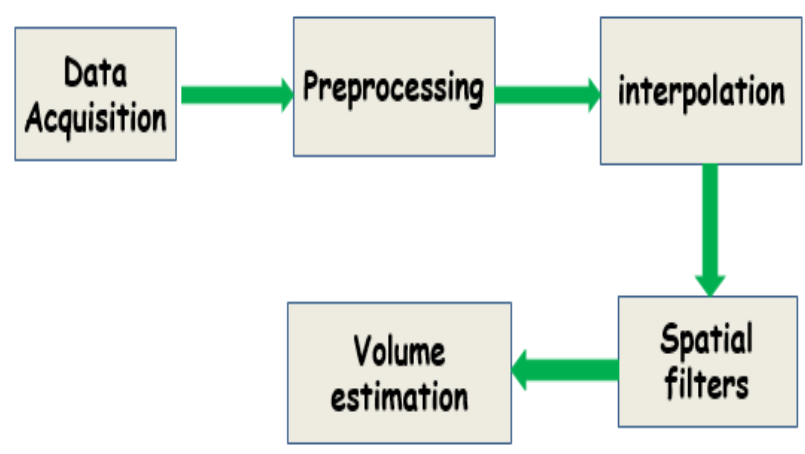

Fig.1. Block Diagram of proposed system

The following block are discuss below in detail.

\section{A. Data Acquisition}

In this Paper, the system designed is based upon the data of a hydropower reservoir near Kannur, Kerala in India. The volume of water in this reservoir is measured from instrument. The data collected is irregularly in nature at the distance of around $6 \mathrm{~m}$.It consists of $\mathrm{X}, \mathrm{Y}$ and $\mathrm{Z}$ values. Where $\mathrm{Z}$ is the depth are measured up to 50 dimension. 


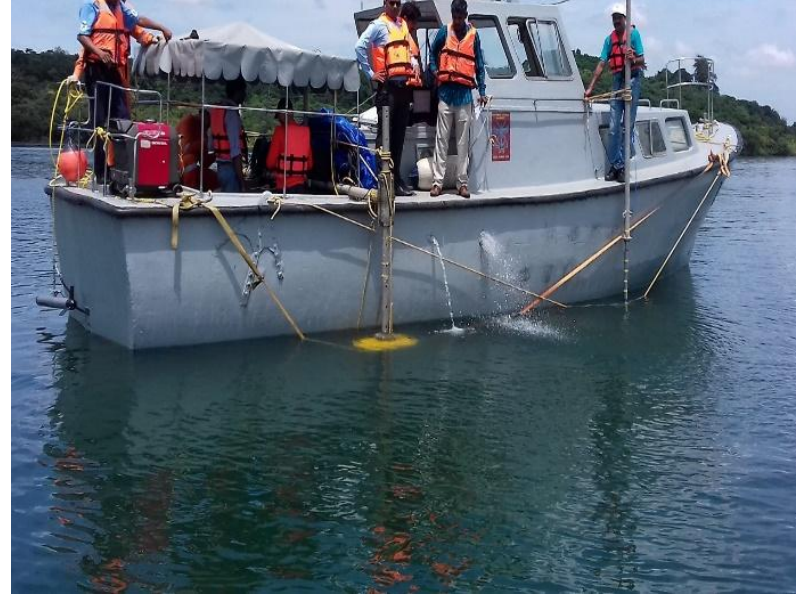

Figure2. Data collection Unit

\section{B. Preprocessing}

The bathymetry data is collected by using dual frequency (Single beam echo sounder) induces multipath noise. The multipath noise occurs due to refraction and reflection of the acoustics signal in water. And also of mangroves present in that Wetland, Which is inside that boundary. The multipath noise is removed by applying stationary wavelet decomposition in the data set [3].

\section{Interpolation}

The Delaunay triangulation algorithm generates a plot composed of triangles space irregularly. The $\mathrm{Z}$ dimension is need to be gridded in a regular manner. The interpolation and gridded data is required for $3 \mathrm{D}$ surface. The interpolation is a Fundamental step in signal processing. Interpolation is done by using triangulation method.

\section{Spatial filter}

The data is non-Stationary in nature consisting so many noise. We don't know exact noise from the analysis got the nature of noise. Which noise is there in the data or samples? Data collection for the different depth. So noise will be added in different states.

\section{E. Volume estimation}

Volume is regularly conveyed quantitatively as a segment of width, or separation crosswise over and tallness or merchantable length. Here and there, various components, for instance, clear bole length are used to evaluate volume. A basic idea is that any components anticipated that would foresee volume should be seen in the midst of field data gathering. Volume is calculated by applying trapezoidal method. Volume is calculated for accuracy of reservoir.

\section{ANALYSIS ON SYNTHETIC DATA}

Below table shows statistical analysis of synthetic data for different noise. In that mean, variance and etc. are compared.

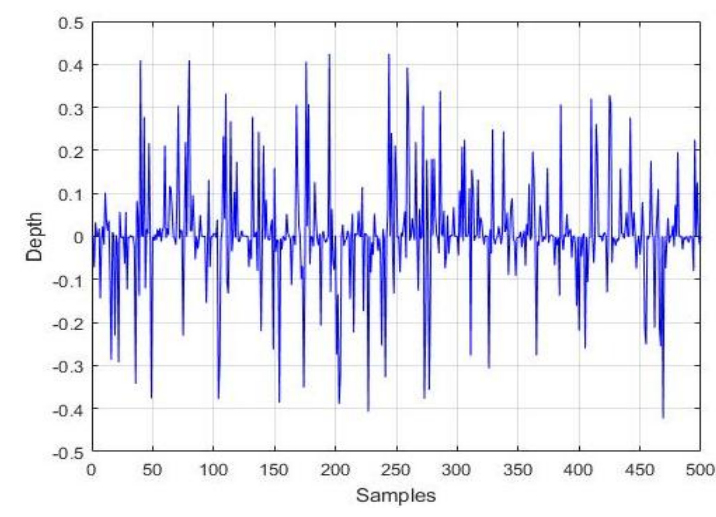

Figure 3.Original plot of synthetic data.

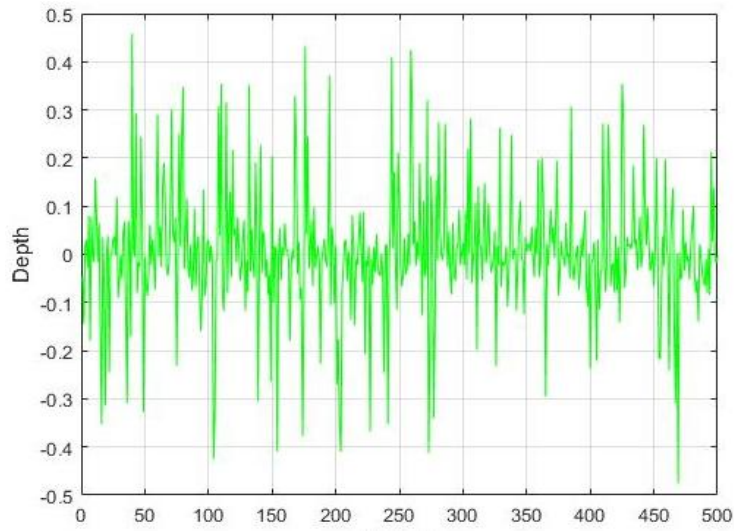

Figure 4.AWGN noise adding in synthetic data.

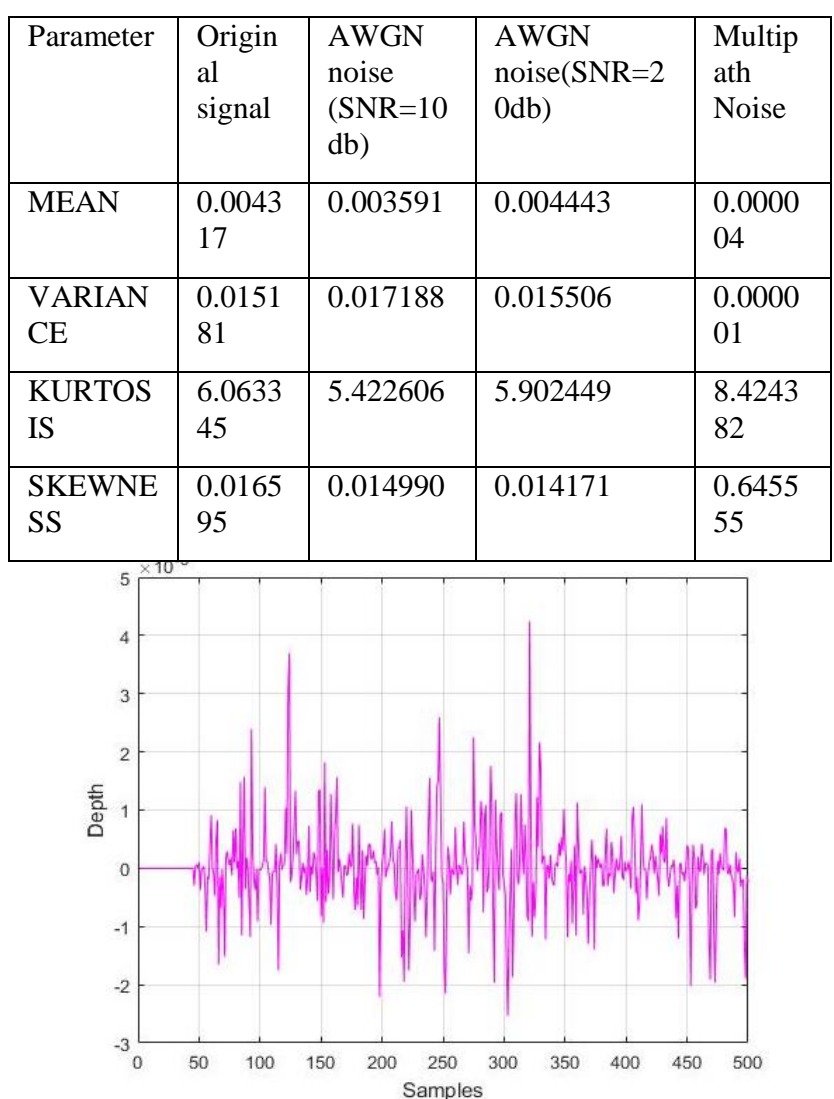

Figure 5.Multipath noise adding in synthetic data. 


\begin{tabular}{|c|c|c|c|}
\hline PARAMETER & VN10 & VN20 & MULTIPATH \\
\hline MEAN & 0.001234 & 0.002463 & -0.000020 \\
\hline VAR & 0.000188 & 0.000059 & 0.000000 \\
\hline KRT & 24.445859 & 6.775138 & 81.982812 \\
\hline SKEW & 0.197303 & $\begin{array}{l}- \\
0.181573\end{array}$ & -0.116736 \\
\hline
\end{tabular}

Above table shows after applying wiener filter on synthetic data

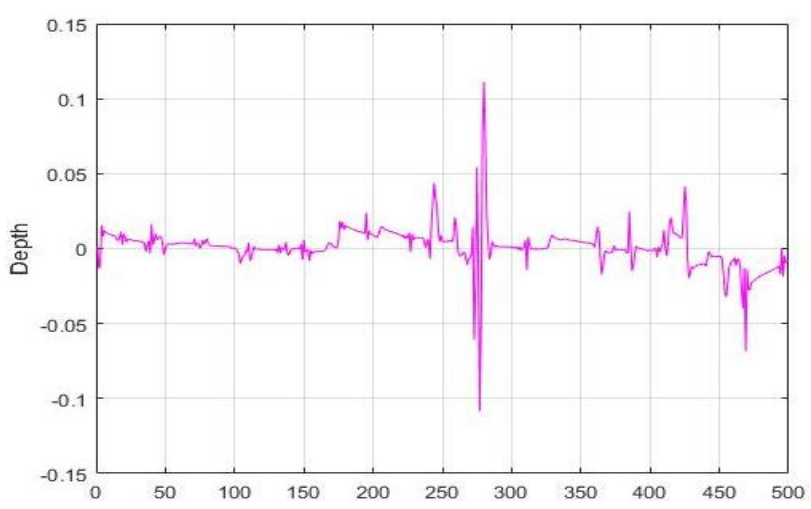

Figure 6.AWGN noise removing by wiener filter.

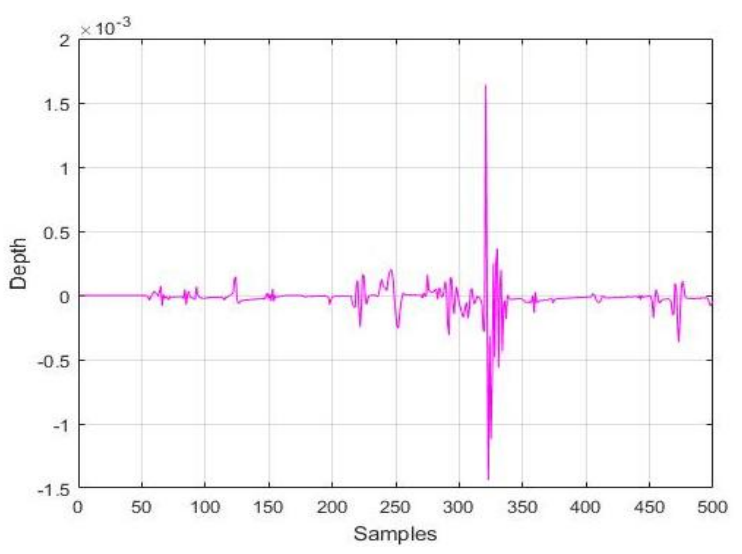

Figure 6.Multipath noise removing by wiener filter.

According to analysis multipath noise is best remove by SWT filter and wiener filter.

\section{RESULTS AND DISCUSSION}

The proposed system is developed in MATLAB. The gridded data bathymetry data gathered utilizing reverberation sounder and GPS in vast size .The data is near about 3032 points in that we analysis of 500 samples. It demonstrates sharp variety in the profundity esteems. The qualities in negative show profundity and tallness underneath the surface of water.

The data is passed from wavelet decomposition by utilizing stationary wavelet change for the denoising. It's demonstrates the edge in the data. Figure 3 appears after Wavelet Decomposition.
The guess coefficient of the decomposition information are than gone through Delaunay triangulation. To counteract base of surface. Figure 4 appears after Interpolation.

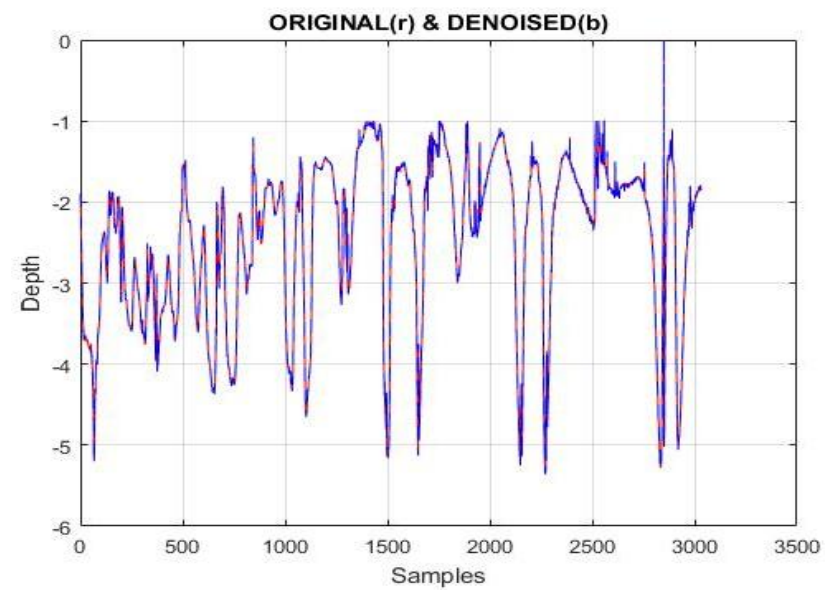

Figure7.Wavelet Decomposition

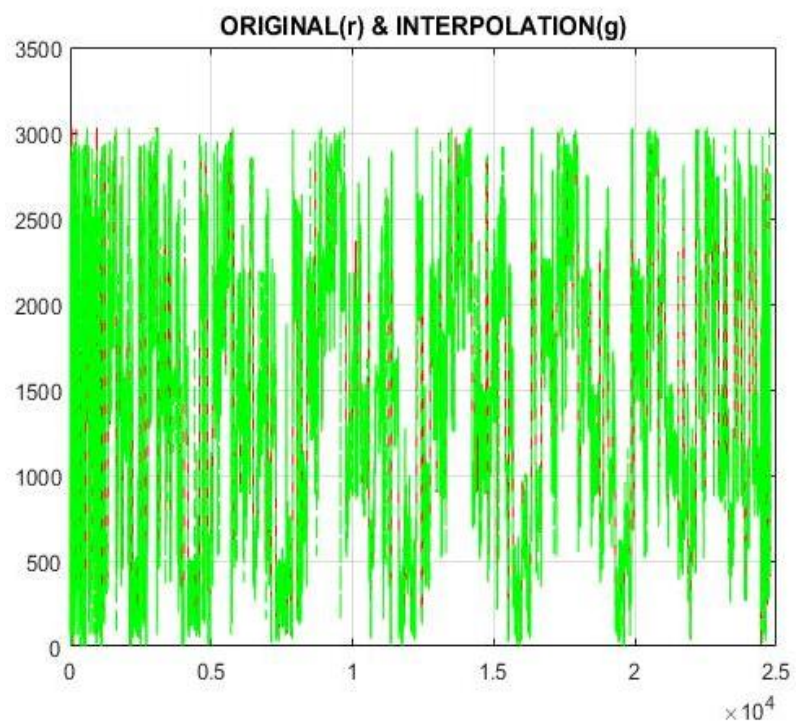

Figure8.Delaunay triangulations

The volume calculates for 500 samples and data is $2021382.000000 \mathrm{~m} 3$. This is almost equivalent to the volume which is ascertained by Surfer Software. This indicates proposed method is better. And value of PSNR is 52.952 and MSE is 0.329

\section{CONCLUSION}

Accurate prediction of volume of water is essential for reservoir water management. This paper presents an interpolation and noise removal techniques that are applied on bathymetry data of a reservoir in Kerala state. These techniques are evaluated on the bathymetry data collected from valapattanam with salt and pepper noise model along with the noises added into the actual bathymetry data collected using dual frequency echo sensor using 200 and 33 KHz. In this paper stationary wavelet change and Delaunay calculation is utilized for triangulation i.e. to change over data into $\mathrm{XYZ}$ point. Weiner filter is utilized for blunder figuring and noise estimation, at last bringing about precise water volume computation. 


\section{ACKNOWLEDGMENTS}

We are thankful to Dr. R.S.Kawitkar, Prof, Dept. of electronics and telecommunication, Sinhgad College of engineering, Pune for his valuable support and guidance.

\section{REFERENCES}

[1] Sushama Shelke, Selva Balan, CRS Kumar,Analysis of Bathymetry Data for Calculating Volumeof Water in a Reservoir, 2016 Conference on Advances in Signal Processing (CASP) Cummins College of Engineering for Women, Pune. Jun 9-11, 2016.

[2] Sonali Vathar, Sushama Shelke, Bathymetry Data Analysis and Depth Measurement, 2016 Online International Conference on Green Engineering and Technologies (IC-GET).

[3] Selva Balan,Arti Khaparde2, Vanita Tank2, Tejashri Rade2and KirtiTakalkar2 under Water Noise Reduction UsingWavelet and Savitzky-Golay.
[4] Ugo Moreaud Philippe Courmontagne Performance Assessment of Noise ReductionMethods Applied to Underwater Acoustic Signals, 978-1-5090-15375/16/\$31.00 (02016 IEEE.

[5] S. Sakthivel Murugan, V. Natarajan, S. Kiruba Veni1 and K. Balagayathri1Analysis of Adaptive Algorithms to Improve the SNR of the Acoustic Signal Affected due to Wind Driven Ambient Noise in Shallow Water Analysis of Adaptive Algorithms to Improve the SNR.

[6] Burdic, William S, Underwater acoustic system analysig, 2nd, Prentice Hall, 1991

[7] Pooja Gavande, Dr. R.S. Kawitkar, M. Selva Balan" Classification of underwater objects using acoustic techniques', ijecs, 2015

[8] Sushma shelke and Selva balan, "Analysis of bathymetry data for shape Prediction of a reservoir", springer.

[9] Yan-yao jiang, "DEvelopmeny of noise reduction algorithm for Underwater singal”,2004,IEEE 